\title{
Research on Electric Parameters Optimization of Electric Guitar Pickup
}

\author{
Cong Tian ${ }^{\mathrm{a}, ~ *, ~ C h a n g ~ S u ~}{ }^{\mathrm{b}}$, Chao Yang \\ Heilongjiang University of Technology, Jixi, Heilongjiang, China, 158100 \\ a5877233@qq.com, bjxdxsc@163.com, ${ }^{\mathrm{a}} \mathrm{jxdxyc@163.com}$ \\ *Corresponding author
}

Keywords: electric guitar; pickup; optimization

\begin{abstract}
The sound of electric guitar mainly depends on the pick-up, which is the most important equipment of electric guitar. It is found that the performance of the pickup depends on its structure, coil diameter, winding number, magnetic size and shape of magnet. In this paper, based on the analysis of working principle, the electrical parameters of the pickup are optimized from the two directions of resistance and inductance, so as to improve its performance. This paper proposes an optimization scheme, builds the circuit model, and proves that the proposed optimization scheme can achieve the optimization effect through the actual test of its performance.
\end{abstract}

\section{Introduction to electric guitar}

Electric guitar is one of the indispensable main musical instruments in pop music, mainly composed of a head, neck, pickup, bridge and guard board. Compared with the traditional guitar, the electric guitar's body is a solid sound box without a resonator device, and is equipped with two or three magnets, namely pickups [1]. Unlike traditional guitars using box vibration to make sound, electric guitars mainly use pickups to pick up acoustic signal amplify it through a loudspeaker, so the pickup is the most important equipment of the electric guitar. Compared with the general guitar, the sound volume of electric guitar can be adjusted by itself and the sound range is larger due to the absence of a resonator. Therefore, its performance flexibility is greatly enhanced, especially in the aspects of tremolo and glide [2].

\section{Operating principle of pickup}

Pick up is the main component of electroacoustic guitar, which determines its timbre in some way. The pickup itself cannot produce sound and has only " signal transmission characteristics", that is, it changes and transmits these signals in its own way after picking up the signal from the vibration of the string like a microphone. For example, installing the same pickup on electric guitars of different materials and structures will result in completely different sounds [3].

There are two basic types of pickup, electromagnetic pickup and piezoelectric pickup. The electromagnetic pickup can only pick up signals from metal strings. The piezoelectric pickup can work with any type of string (metal string, nylon string). There are two types of electromagnetic pickup: single coil pickup and dual coil pickup. Single coil pickups are very sensitive to changes in interference of magnetic field. The dual coil pickup uses two specially connected coils to eliminate interference by sending the same signal of the two coils at the same amplitude and opposite phase.

The working principle of the pickup is as follows: the electromagnetic pickup is mainly composed of a magnet and an insulated copper coil,in which the wire is wound into a coil on the magnet and the coil is connected to the loudspeaker ( as shown in Fig. 1). The magnetic field generated by the pickup magnet magnetizes the string, which in turn generates its own magnetic field. When the strings are stationary, the magnetic flux through the coil is a constant. When the string vibrates, it moves relative to the coil, and the magnetic flux passing through the coil changes. 


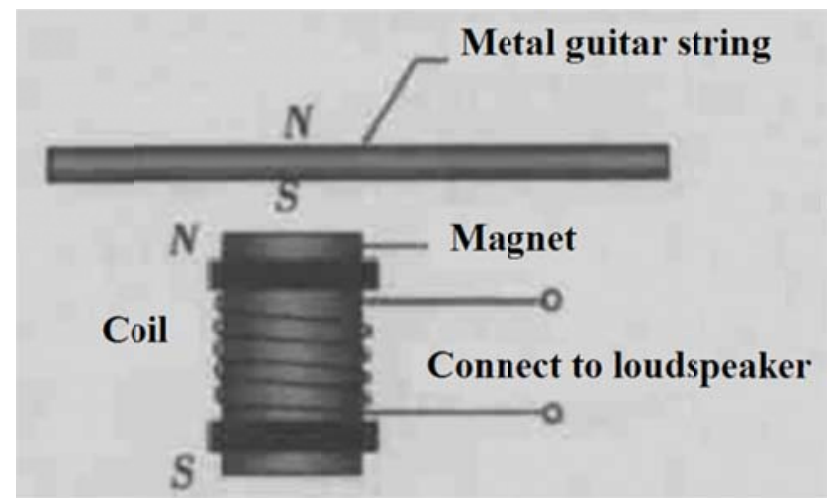

Fig. 1 Electromagnetic pickup

Faraday's law of electromagnetic induction states that when the magnetic flux $\phi_{m}$ in the closed loop changes, the induced electromotive force generated in the loop is proportional to the rate of change of the magnetic flux to time, that is:

$$
\varepsilon=-\frac{d \phi_{m}}{d t}
$$

If the resistance of the loop is $R$, the induced current $I$ in the loop is:

$$
I=-\frac{1}{R} \frac{d \phi_{m}}{d t}
$$

Vibrating strings will generate induced electromotive force, the amplitude of which is proportional to the vibration frequency of the strings, so induced current will be generated in the coil at the same frequency as the string vibration. This inductive current can be amplified and restored through the loudspeaker, and the sound played by the electric guitar can be heard [4].

\section{Electric parameters optimization of electric guitar pickup}

\subsection{Equivalent circuit of pickup.}

The actual pickup consists of a conductor coil, a plurality of magnets surrounded by the coil, and a frame for fixing. When playing the string, the string cuts the magnetic induction line, which generates induced electromotive force and generates an inductive current in the loop, which flows to the amplifier through the external wiring, thus producing sound. In terms of electrical characteristics, the pickup can be equivalent to an RLC resonant circuit, as shown in Fig. 2. The parameters of each component affect $R, L$ and $C$ parameters in the circuit model, so as to influence the resonant frequency point of the output signal. The overtones in the range around the resonant frequency point will be amplified (the fundamental tone will not be affected), while those overtones far away from the resonant frequency point will be rapidly reduced.

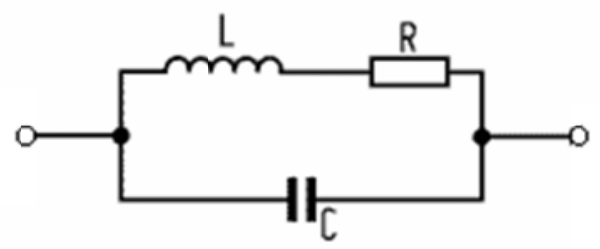

Fig. 2 Electrical equivalent circuit of a magnetic pickup

A real coil can be described as an ideal inductor $L$ in series with a resistor $R$, and in parallel with capacitance $C$ between lines. The inductance $L$ is the main parameter, which is determined by the number of turns of the coil, magnetic core material and the overall geometry of the coil. The resistance and the capacitance don't have much influence and can be neglected. When the strings are moving, an AC voltage is induced in the coil. So the pickup acts like an AC source with some 
attached electric components. The external load consists of resistance (the volume and tone potentiometer in the guitar, and any resistance to ground at the amplifier input) and capacitance (due to the capacitance between the hot lead and shield in the guitar cable). The cable capacitance is significant and must not be neglected. This arrangement of passive components forms a so-called second-order low-pass filter [5], as shown in Fig. 3.

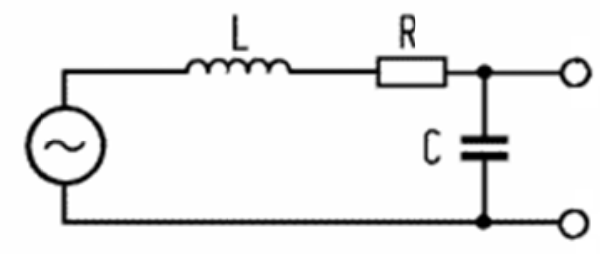

Fig. 3 A pickup as an audio voltage source plus second-order low-pass filter

\subsection{Optimization scheme of electrical parameters of pickup.}

In an electric guitar factory, the X-type pickup is the most common pick up with the most extensive use. This pickup is selected for research and its electrical parameters are optimized to improve its performance. There are many electrical parameters of the pickup, such as DC resistance, inductance, capacitance, impedance, mass parameters, dissipation, resonance frequency, resonance peak, etc. Among them, both the thickness of copper wire coil and the number of winding turns of copper wire have influence on DC resistance. The resistance is related to the volume, the inductance is related to the tone quality and the volume, and the capacitance is only for reference. The tone power of the pickup depends on the DC resistance and the resonance peak value. Therefore, this paper mainly improves the pickup performance from the two directions of resistance and inductance, with capacitance as the reference value.

The number of turns, magnet material and wire diameter of the pickup have different effects on its performance, as shown in the following tables. Table 1 and table 2 show some relevant data of the X pickup, as well as the pickup reference data of other 3 companies.

Table 1 Reference data of neck pickup

\begin{tabular}{ccccccccc}
\hline Type/magnet & $\begin{array}{c}\text { Number } \\
\text { of turns }\end{array}$ & $\begin{array}{c}\text { Wire } \\
\text { diameter } \\
{[\mathrm{mm}]}\end{array}$ & $\begin{array}{c}\mathrm{R} \\
{[K \Omega]}\end{array}$ & $\mathrm{Q}$ & $\begin{array}{c}\mathrm{Z} \\
{[\mathrm{K} \Omega]}\end{array}$ & $\begin{array}{c}\mathrm{L} \\
{[\mathrm{H}]}\end{array}$ & $\begin{array}{c}\mathrm{C} \\
{[\mathrm{nF}]}\end{array}$ & $\mathrm{D}$ \\
\hline $\mathrm{X} /$ white & 4900 & 0.055 & 9.82 & 0.3 & 10.26 & 4.75 & 533.1 & 3.29 \\
$\mathrm{X} /$ white & 4800 & 0.055 & 9.67 & 0.29 & 10.09 & 4.59 & 442.4 & 3.69 \\
$\begin{array}{c}\text { X/black } \\
\text { X/white }\end{array}$ & 5650 & 0.05 & 13.28 & 0.27 & 10.09 & 4.59 & 550.9 & 3.69 \\
$\begin{array}{c}\text { Company 1 } \\
\text { /white }\end{array}$ & 5600 & 0.05 & 13.3 & 0.28 & 13.66 & 6 & 421.7 & 3.48 \\
$\begin{array}{c}\text { Company 2 } \\
\text { /black }\end{array}$ & & 0.05 & 7.48 & 0.34 & 7.89 & 4.03 & 627.6 & 2.95 \\
$\begin{array}{c}\text { Company 3 } \\
\text { /black }\end{array}$ & 6000 & 0.045 & 16.15 & 0.2 & 16.49 & 5.28 & 478.8 & 4.86 \\
$\begin{array}{c}\text { Company 3 } \\
\text { /white }\end{array}$ & 5600 & 0.045 & 15.47 & 0.27 & 16.01 & 6.57 & 385 & 3.74 \\
$\begin{array}{c}\text { Company 3 } \\
\text { /white }\end{array}$ & 6200 & 0.05 & 13.14 & 0.26 & 13.6 & 5.62 & 451.1 & 3.72 \\
$\begin{array}{c}\text { Company 3 } \\
\text { /black }\end{array}$ & 6400 & 0.05 & 13.35 & 0.26 & 13.8 & 5.6 & 452.6 & 3.79 \\
\hline
\end{tabular}


Table 2 Reference data of body pickup

\begin{tabular}{ccccccccc}
\hline Type/magnet & $\begin{array}{c}\text { Number } \\
\text { of turns }\end{array}$ & $\begin{array}{c}\text { Wire } \\
\text { diameter } \\
{[\mathrm{mm}]}\end{array}$ & $\begin{array}{c}\mathrm{R} \\
{[\mathrm{K} \Omega]}\end{array}$ & $\mathrm{Q}$ & $\begin{array}{c}\mathrm{Z} \\
{[K \Omega]}\end{array}$ & $\begin{array}{c}\mathrm{L} \\
{[\mathrm{H}]}\end{array}$ & $\begin{array}{c}\mathrm{C} \\
{[\mathrm{nF}]}\end{array}$ & $\mathrm{D}$ \\
\hline $\begin{array}{c}\text { X/white } \\
\text { X/black }\end{array}$ & 5300 & 0.055 & 10.73 & 0.32 & 11.27 & 5.47 & 462.7 & 3.12 \\
$\begin{array}{c}\text { X/black } \\
\text { X/black }\end{array}$ & 5600 & 0.055 & 10.53 & 0.28 & 10.96 & 4.78 & 529.1 & 3.5 \\
$\begin{array}{c}\text { Company } 1 \\
\text { /white }\end{array}$ & 6000 & 0.05 & 14.18 & 0.28 & 14.78 & 6.33 & 399.6 & 3.56 \\
$\begin{array}{c}\text { Company } 2 \\
\text { /black }\end{array}$ & & 0.05 & 8.08 & 0.30 & 8.42 & 3.81 & 662 & 3.37 \\
$\begin{array}{c}\text { Company } 3 \\
\text { /white }\end{array}$ & 6600 & 0.05 & 14.43 & 0.28 & 14.98 & 6.43 & 393.7 & 3.56 \\
$\begin{array}{c}\text { Company } 3 \\
\text { /black }\end{array}$ & 6800 & 0.05 & 14.92 & 0.27 & 15.46 & 6.44 & 392.7 & 3.68 \\
$\begin{array}{c}\text { Company 3 } \\
\text { /black }\end{array}$ & 6300 & 0.045 & 17.55 & 0.21 & 17.94 & 5.93 & 426.6 & 4.7 \\
$\begin{array}{c}\text { Company 3 } \\
\text { /white }\end{array}$ & 6000 & 0.045 & 16.5 & 0.27 & 17.1 & 7.13 & 355 & 3.68 \\
\hline
\end{tabular}

Based on the analysis of the current data of the pickups of guitar factory and other three major companies, it is found that the pickups with the same number of turns of the clamp but different magnet magnetism also have different performances. It is not that the more coils the pickup clip winds, the better. The more coils, the deeper the sound. Through practical tests, it is found that white magnets with strong magnetism are better than black magnets with weak magnetism, so white magnets are used in this paper. The following three optimization schemes are proposed. Through comparison, analysis and tuning test, the optimal scheme is selected.

Scheme 1. The number of turns of X-neck pickup is selected as 5600 turns, and its electrical parameters are measured as $\mathrm{R}=13.16 \mathrm{~K} \Omega, \mathrm{L}=7.47 \mathrm{H}$, and $\mathrm{C}=484.6 \mathrm{nF}$. The number of turns of the body pickup is 6,000 , and the electrical parameters are measured as $\mathrm{R}=14.25 \mathrm{~K} \Omega, \mathrm{L}=7.04 \mathrm{H}$, and $\mathrm{C}=359.6 \mathrm{nF}$.

When the finished pickups are installed on electric guitars, a wild style of sound can be heard. When tuning, it was found that the sound volume from the two pickups did not differ much, so the pickups were not selected. When tuning, it is found that the volume and timbre do not differ very much in both pickups, so this pickup is not selected.

Scheme 2. Since the volume and timbre of the two pickups in Scheme 1 are not much different, the number of turns of the neck pickup is reduced in scheme 2. The final number of turns is 5,200, and the electrical parameters are measured as $\mathrm{R}=11.27 \mathrm{~K} \Omega, \mathrm{L}=4.85 \mathrm{H}, \mathrm{C}=512 \mathrm{nF}$; the number of turns of the body pickup is 6,000 , and the electrical parameters are measured as $\mathrm{R}=13.17 \mathrm{~K} \Omega$, $\mathrm{L}=4.7 \mathrm{H}, \mathrm{C}=562.7 \mathrm{nF}$ 。

Install the pickups on the electric guitar and tune them. It is found that the neck and body pickups feel completely different when playing, and the sound volume difference is too large. So this scheme is not selected.

Scheme 3. In scheme 2, it is found that the difference of feeling between the neck and body pickups when playing is too large, so the number of turns of X-type pickups will be reduced in scheme 3 . When the number of turns drops to 4900 , the electrical parameters of the neck pickup are measured as $\mathrm{R}=11.86 \mathrm{~K} \Omega, \mathrm{L}=4.78 \mathrm{H}, \mathrm{C}=530.4 \mathrm{nF}$. When the number of turns drops to 5600 , the electrical parameters of the body pickup are measured as $\mathrm{R}=13.32 \mathrm{~K} \Omega, \mathrm{L}=5.21 \mathrm{H}, \mathrm{C}=560.5 \mathrm{nF}$. 
Install the pickups on the electric guitar and tune them. It is found that the sound of the neck and body pickups is clear and powerful when playing, reaching the expected value, so this scheme is finally chosen. The data of X-type electric guitar pickup measured in the three schemes are shown in Table 3. Fig. 4 and Fig. 5 are equivalent circuit diagrams of the electric guitar neck pickup and body pickup respectively in this optimization scheme.

Table 3 Pickup data measured in 3 schemes

\begin{tabular}{|c|c|c|c|c|c|c|c|c|c|}
\hline Scheme & Type/magnet & $\begin{array}{l}\text { Number } \\
\text { of turns }\end{array}$ & $\begin{array}{c}\text { Wire } \\
\text { diameter } \\
{[\mathrm{mm}]}\end{array}$ & $\begin{array}{c}\mathrm{R} \\
{[K \Omega]}\end{array}$ & $\mathrm{Q}$ & $\begin{array}{c}\mathrm{Z} \\
{[K \Omega]}\end{array}$ & $\begin{array}{c}\mathrm{L} \\
{[\mathrm{H}]}\end{array}$ & $\begin{array}{c}\mathrm{C} \\
{[\mathrm{nF}]}\end{array}$ & $\mathrm{D}$ \\
\hline \multirow{2}{*}{1} & $\begin{array}{l}\text { X/white } \\
\text { (Neck) }\end{array}$ & 5600 & 0.05 & 13.16 & 0.28 & 13.7 & 7.47 & 484.6 & 4.67 \\
\hline & $\begin{array}{c}\text { X/white } \\
\text { (Body) }\end{array}$ & 6000 & 0.05 & 14.25 & 0.31 & 14.91 & 7.04 & 359.6 & 3.21 \\
\hline \multirow{2}{*}{2} & $\begin{array}{l}\mathrm{X} / \text { white } \\
\text { (Neck) }\end{array}$ & 5200 & 0.05 & 11.27 & 0.27 & 10.67 & 4.85 & 512.0 & 3.69 \\
\hline & $\begin{array}{c}\text { X/white } \\
\text { (Body) }\end{array}$ & 6000 & 0.05 & 13.17 & 0.21 & 13.46 & 4.70 & 562.7 & 3.12 \\
\hline \multirow[t]{2}{*}{3} & $\begin{array}{l}\text { X/white } \\
\text { (Neck) }\end{array}$ & 4900 & 0.05 & 11.86 & 0.25 & 12.23 & 4.78 & 530.4 & 3.95 \\
\hline & $\begin{array}{c}\mathrm{X} / \text { white } \\
\text { (Body) }\end{array}$ & 5600 & 0.05 & 13.32 & 0.32 & 12.25 & 5.21 & 560.5 & 3.92 \\
\hline
\end{tabular}

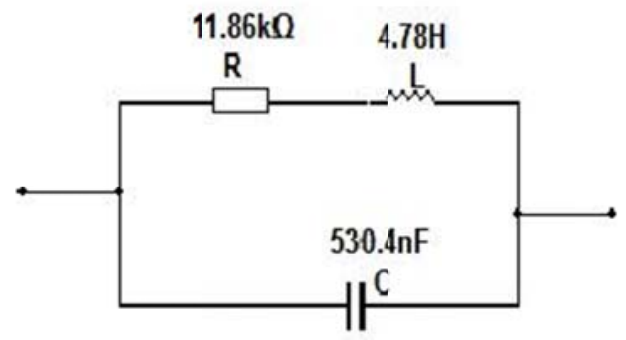

Fig. 4 Circuit model of neck pickup

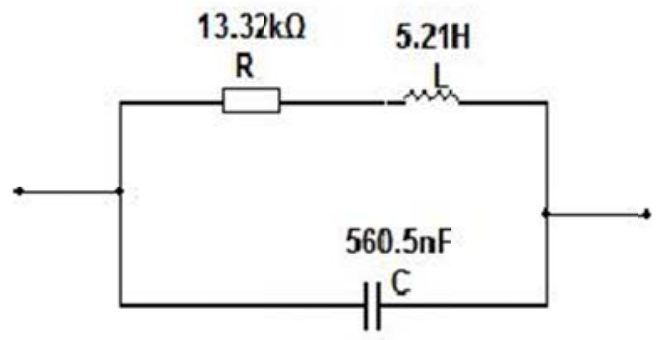

Fig. 5 Circuit model of body pickup

\subsection{Verification of optimization scheme.}

According to Scheme 3, the pickup is made and tested by oscilloscope, signal generator and AC microvoltmeter. Through 10 sets of X pickup test data, it is found that the measured data have been fluctuating within the approximate range of the data measured by the optimization scheme. During the test, a signal of $1000 \mathrm{~Hz}$ was given by the signal generator. At this time, the $\mathrm{X}$ pickup was measured at $1.1 \mathrm{KHz}$ and the peak value of the waveform measured by the AC microvoltmeter was $20 \mathrm{mV}$. The frequency waveform diagram is shown in Fig. 6. When the signal generator gave a signal of $500 \mathrm{~Hz}$, the pickup was measured at $502 \mathrm{~Hz}$, and the peak value of waveform measured by $\mathrm{AC}$ microvoltmeter was $30 \mathrm{mV}$. The frequency waveform diagram is shown in Fig. 7. 




Fig. 6 Frequency waveform diagram of $1 \mathrm{KHz}$

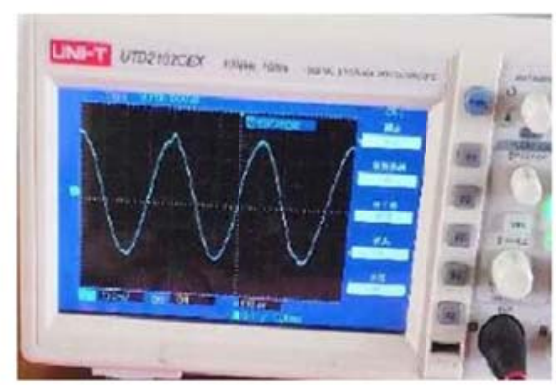

Fig. 7 Frequency waveform diagram of $500 \mathrm{~Hz}$

By analyzing the waveform diagram and test results, it can be concluded that the faster the frequency of the pickup, the clearer the timbre of the pickup; The higher the frequency peak, the greater the volume of the pickup. After installing the pickup on the electric guitar, the tuning results show that the tone of the neck and body pickup was clear and pure when playing, and reached the desired value. Therefore, it is proved that Scheme 3 achieves the optimized effect.

\section{Conclusion}

The performance of pickup depends on its structure, winding diameter, number of turns, magnet magnetism and magnet shape, etc. Generally speaking, the more coil turns, the greater the DC resistance, the greater the output power and the lower the high pitch. Through research, it is found that:

The main factors influencing the performance of the pickup include coil turns (i.e. the DC resistance of the pickup) and the magnetic intensity of the magnet inside the pickup. The thickness and number of turns of the copper wire in the pickup coil have an influence on the resistance. The resistance is related to the volume, the inductance is related to the tone quality and the volume, and the capacitance is only for reference.

Changing the diameter of the enameled wire can change the resistance of the pickup. Theoretically, when the number of winding turns of the wire clamp and the resistivity of the enameled wire are constant, the thinner the diameter of the enameled wire, the larger the resistance of the pickup, but it cannot increase indefinitely. The increase in the number of turns is accompanied by a decrease in the high pitch.

Theoretically, the less $\mathrm{D}$ (i.e. dissipation) in the measured data, the better the pickup performance.

The material, manufacturing process and shell of the pickup will also affect the performance of the pickup.

This paper focuses on the electrical parameters optimization of electric guitar pickup. Based on the analysis and study of the existing data of electric guitar factory, an optimization scheme is proposed, and the validity of the scheme is verified through tests. There are still some shortcomings in this research, which need to be improved. For example, the improvement can be put forward from the aspects of coil tightness, magnet strength and so on, so as to achieve the goal of parameter optimization. It is believed that more and more new improvement plans will be put forward in the future.

\section{Acknowledgements}

This research is supported by planning topic of education science in Heilongjiang province in 2017. The name of the project is "Based on the TRIZ theory build the core curriculum group of electrical engineering major and research on the cultivation of students' innovative ability". This research is also supported by the science and technology plan project in Jixi city. The name of the project is "Research on wireless audio transmission system based on electric guitar". 


\section{References}

[1] F. Zhu, H.W. Zheng and H.J. Liang: Modern physics, Vol. 16 (2004) No.4, p.44

[2] T. Qin: Musical Instrument, Vol. 42 (2013) No.7, p.90-93

[3] W.G. Cao: Musical Instrument Magazine, Vol. 31 (2002) No.7, p.32-33.

[4] K.Y. Dou: the Design and Related Practice Research of Electric Guitar (MS., Shenyang Jianzhu University, China 2013), p.21-22

[5] Information on http://www.buildyourguitar.com/resources/lemme/index.htm 